\title{
BRISA DO RIO TAPAJÓS E SUA INFLUÊNCIA NA ATMOSFERA
}

\author{
Raphael Tapajós ${ }^{1, *}$, Wilderclay Machado ${ }^{1}$, Diego Aguiar ${ }^{1}$, Bruno Bota $^{1}$, Kenia Weidemann ${ }^{2}$, \\ Alírio Furtado Neto ${ }^{1}$, Rodrigo da Silva ${ }^{1}$, David Fitzjarrald ${ }^{3}$ \\ ${ }^{1}$ Universidade Federal do Oeste do Pará ${ }^{1}$ \\ ${ }^{2}$ Harvard University \\ ${ }^{3}$ Albany University \\ *rpablotapajos@ hotmail.com
}

\section{RESUMO}

O contraste térmico entre o rio Tapajós e FLONA Tapajós aliado às ocorrências de ventos alísios fracos faz com que ocorra a brisa no sentido rio-floresta, alterando significativamente as características termodinâmicas da CLA local. Os resultados mostram que existe um horário padrão de término da brisa de rio com mais de duas horas, de duração até às 18 horas, com início variável. As sondagens com balão cativo não apresentam padrões característicos, ocorrendo ou não brisa do rio e, em outras, duas camadas de ar acopladas com características bem definidas com informações do rio e floresta.

\section{INTRODUÇÃO}

A estrutura termodinâmica da Camada Limite Atmosférica (CLA) é definida por características da superfície. Na Amazônia, com a predominância de rios e lagos, deve-se levar em consideração as diferenças de capacidade térmica apresentada entre corpos d'água e a superfície que o rodeia. Assim, forçantes térmicos, devido à presença de rios, induzem o comportamento climático e influenciam nas condições da atmosfera local (SILVA DIAS et al., 2004; LU et al., 2005).

O presente trabalho avaliou os padrões de ocorrência da brisa do rio Tapajós (ventos de oeste) e sua influência nas características da CLA local por meio de sondagens.

\section{MATERIAL E MÉTODO}

A campanha de medidas ocorreu entre os dias 14 a 25 (exceto dia 22) de junho de 2011 no oeste do Pará nos limites do município de Belterra, na margem leste do rio Tapajós, especificamente na área da Floresta Nacional do Tapajós (FLONA Tapajós), na comunidade de Jamaraquá $\left(-2,80639^{\circ} \mathrm{S} ;-55,03639^{\circ} \mathrm{O}\right)$.

Para a obtenção dos dados de perfis atmosféricos realizou-se sondagens com balão cativo de $4 \mathrm{~m}^{3}$. As medidas foram realizadas através da Sonda AIR (temperatura, umidade, velocidade e direção do vento). Além das sondagens, dados adicionais da estação meteorológica local foram analisados. 


\section{RESULTADOS E DISCUSSÃO}

\section{DADOS DA TORRE METEOROLÓGICA}

Entre os dias 14 e 26, observou-se a brisa do rio em 6 dias, sendo que em 4 dias a brisa teve duração entre 3 e 7 horas, como mostrado na Figura 1. Em 2 dias a brisa teve duração de menos de 2 horas, e nos outros 7 dias não houve brisa do rio. Não houve padrão de inicio brisa do rio, mas, em dois dias durou mais de 2 horas (dias 20 e 23). Em outros dias, a brisa iniciou sempre após o meio dia, até às 15 horas. Já os horários de fim da brisa do rio, com mais de duas horas, obedecem a um padrão, cessando ao redor de 18 horas.

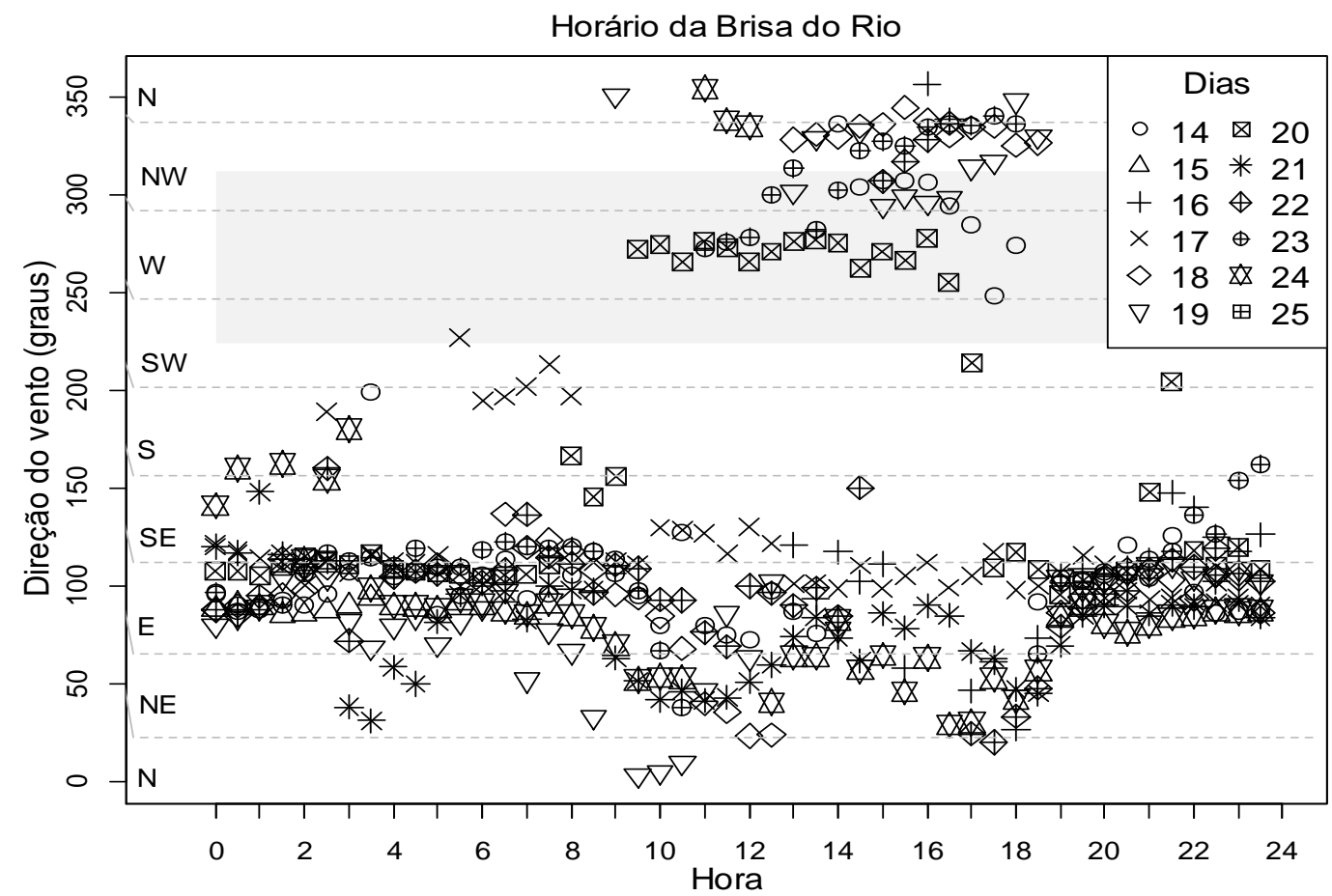

Figura 1. Horário e dias em que ocorre a brisa do rio Tapajós. Área em cinza indica a ocorrência de brisa do rio

A intensidade da brisa do rio varia de dia para dia, porém em média temos valores de velocidade do vento de $2 \mathrm{~m} / \mathrm{s}$. A velocidade pode atingir máximos de $3,5 \mathrm{~m} / \mathrm{s}$ (dias 14 e 22) e mínimos de $0,3 \mathrm{~m} / \mathrm{s}$, sendo que os valores mínimos são atingidos quando o a direção do vento começa a mudar para Leste.

\section{DADOS DO BALÃO CATIVO}

Em oito sondagens feitas entre 16 e 20 horas, observamos brisa do rio. Porém, há uma grande variabilidade das características da CLA, com e sem a ocorrência de brisa, principalmente na Temperatura Potencial (TP) e umidade específica (UE), como nas sondagens apresentadas da Figura 2. 


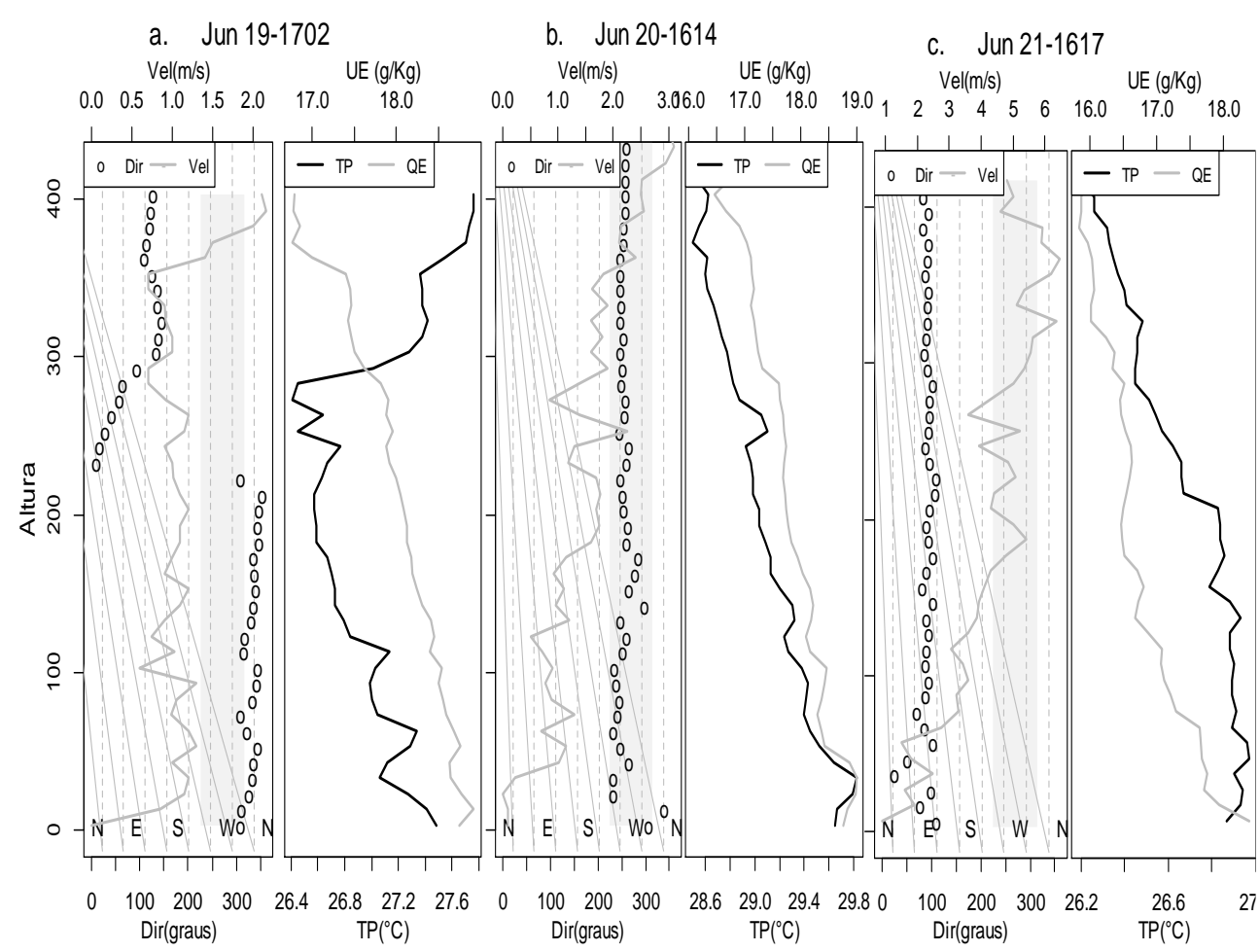

Figura 2. Sondagens com e sem brisa do rio. Área em cinza indica a ocorrência de brisa do rio. (a) 19 de junho, 1702(LT). (b) 20 de junho, 1614 (LT). c 21 de junho, 1617 (LT).

A Figura 2a apresenta sondagem típica nos horários em que a brisa do rio Cessa, como discutido na seção anterior, caracterizando o acoplamento de duas camadas, uma com características do rio e outra, logo acima, com características da floresta. Verifica-se que quando o vento muda de direção, a temperatura potencial aumenta bruscamente devido a camada com aos ventos oriundos de leste, que trazem consigo característica de uma camada bem aquecida (dia ensolarado) e misturada durante o dia.

A figura $2 \mathrm{~b}$ mostra uma sondagem caracterizada pela constante brisa do rio por todo perfil sondado, e a Figura $2 \mathrm{c}$ sondagem feita no dia seguinte, praticamente no mesmo horário, mas sem a presença da brisa do rio. A sondagem (b) apresenta temperatura potencial elevada, resultado do armazenamento de energia radiativa que o rio recebeu durante dia (dia ensolarado), sendo que grande parte desta energia também é usada para evaporar a água do rio, trazendo ar mais úmido. Como o dia 21 foi um dia nublado e a sondagem (c) trás informações sobre a floresta, apresenta valores menores para temperatura potencial.

\section{CONCLUSÕES}

A partir dos dados da estação meteorológica, verificou-se que a brisa do rio tem horário definido para cessar quando ocorre por mais de 2 horas de duração.

Nas sondagens com brisa de rio identificada, é possível verificar nitidamente a diferença na temperatura potencial e umidade específica em níveis que se tem ar com a influência do rio e ar da floresta. A diferença é significativa, principalmente quando ocorre uma divisão visível em duas camadas acopladas com características distintas. 


\section{AGRADECIMENTOS}

Os autores agradecem ao apoio da CAPES e do Programa de Grande Escala Biosfera (LBA/Santarém).

\section{BIBLIOGRAFIA}

LU, L.; DENNING, A. S.; SILVA-DIAS, M. A.; SILVA-DIAS, P.; LONGO, M.; FREITAS, S. R.; SAATCHI, S. Mesoscale circulations and atmospheric. $\mathrm{CO}_{2}$ variations in the Tapajós Region, Pará, Brazil. Journal of Geophysical Research, vol. 110, 2005.

SILVA DIAS, M. A. F.; SILVA DIAS P. L.; LONGO M.; FITZJARRALD D. R.; DENNING A. S. River breeze circulation in eastern Amazonia: observations and modelling results, Theoretical and Applied Climatology, vol. 78(1), p. 111-121, 2004. 